\title{
Identifying Faculty and Peer Interaction Patterns of First-Year Biology Doctoral Students: A Latent Class Analysis
}

\section{Soojeong Jeong, ${ }^{\ddagger *}$ Jennifer M. Blaney\$, and David F. Feldon ${ }^{\dagger}$}

'Department of Instructional Technology and Learning Sciences, Utah State University, Logan, UT 84322; \$Department of School Psychology and Educational Leadership, Idaho State University, Pocatello, ID 83202

\begin{abstract}
Faculty and peer interactions play a key role in shaping graduate student socialization. Yet, within the literature on graduate student socialization, researchers have primarily focused on understanding the nature and impact of faculty alone, and much less is known about how peer interactions also contribute to graduate student outcomes. Using a national sample of first-year biology doctoral students, this study reveals distinct categories that classify patterns of faculty and peer interaction. Further, we document inequities such that certain groups (e.g., underrepresented minority students) report constrained types of interactions with faculty and peers. Finally, we connect faculty and peer interaction patterns to student outcomes. Our findings reveal that, while the classification of faculty and peer interactions predicted affective and experiential outcomes (e.g., sense of belonging, satisfaction with academic development), it was not a consistent predictor of more central outcomes of the doctoral socialization process (e.g., research skills, commitment to degree). These and other findings are discussed, focusing on implications for future research, theory, and practice related to graduate training.
\end{abstract}

\section{INTRODUCTION}

Doctoral training is largely understood through a socialization framework. As Bragg (1976, p. 1) explained, the graduate socialization process describes how a student "acquires the knowledge and skills, the values and attitudes, and the habits and modes of thought ... all learning - the affective as well as the cognitive." Within graduate socialization theory, both faculty and peers serve as key socialization agents that shape training experiences and related outcomes (Weidman et al., 2001; Austin, 2002; Gardner, 2007). Researchers argue that these socialization experiences in the early stages of doctoral study have a critical impact on student retention (Golde, 1998, 2000; Lovitts, 2001) and subsequent academic achievement (Paglis et al., 2006). Interactions with faculty and peers may be of particular importance in science-related disciplines, in which laboratory-based group research is dominant (Cumming, 2009; Stephan, 2012).

A substantial number of studies have identified different types of support that faculty members provide to their students and have documented the associations between faculty support and doctoral outcomes (e.g., Tenenbaum et al., 2001; Zhao et al., 2007; Gardner, 2010; Noy and Ray, 2012). Fewer studies of graduate socialization also have taken peer interactions into account (e.g., Flores-Scott and Nerad, 2012; Meschitti, 2018), yielding promising findings that warrant further exploration. However, existing studies typically adopt qualitative approaches, which limits the generalizability of the findings. Conversely, existing quantitative studies tend to rely on variable-centered methods, which can obscure individual variation in the way students interact with both faculty and peers (i.e., previous studies tend to consider faculty interactions and peer interactions as independent from each other). The current study examines faculty and peer interactions through the lens of person-oriented analyses,
Derek Braun, Monitoring Editor

Submitted May 14, 2019; Revised Aug 20, 2019; Accepted Aug 26, 2019

CBE Life Sci Educ December 1, 2019 18:ar59 DOI:10.1187/cbe.19-05-0089

"Present address: Learning and Cognition Lab, Mary Lou Fulton College of Education, Arizona State University, Tempe, AZ 85281.

*Address correspondence to: Soojeong Jeong (soo.jeong@asu.edu).

(ㄷ) 2019 S. Jeong et al. CBE-Life Sciences

Education @ 2019 The American Society for Cell Biology. This article is distributed by The American Society for Cell Biology under license from the author(s). It is available to the public under an Attribution-Noncommercial-Share Alike 3.0 Unported Creative Commons License (http:// creativecommons.org/licenses/by-nc-sa/3.0) "ASCB®" and "The American Society for Cell Biology ${ }^{\prime}$ " are registered trademarks of The American Society for Cell Biology. 
with the intent of identifying "latent classes" or categories that capture consistent patterns of socialization that emerge across individuals.

Using a national sample of first-year biology doctoral students, this study aims to 1) identify and classify doctoral student faculty and peer interaction patterns, 2) investigate associations between students' interaction classifications and their demographic characteristics, and 3) connect students' faculty and peer interaction profiles to a wide range of affective and cognitive doctoral outcomes.

\section{LITERATURE REVIEW}

\section{Doctoral Socialization Theory}

Guided by socialization theories (Weidman et al., 2001; Weidman, 2010; Austin, 2002), this study focuses on first-year doctoral student experiences in biology departments. From this perspective, doctoral training is a process through which students develop and internalize essential knowledge, skills, behaviors, norms, and identities for becoming members in their chosen scholarly fields.

However, given that different academic disciplines and fields have their own structures, cultures, values, and scholarly practices, doctoral students' experiences necessarily differ depending on the departments and programs to which they belong (Austin, 2002; Golde, 2005; Gardner, 2007; Zhao et al., 2007). For instance, biology primarily relies on team-based laboratory research (Cumming, 2009; Stephan, 2012), so the research laboratory functions as the central site of socialization (Golde, 1998). These students' training activities are, relative to humanities disciplines, more collaborative in nature and entail more frequent interactions with their faculty mentors and peers (Turner et al., 2002). Such differences between disciplines highlight the importance of examining socialization experiences within specific disciplinary contexts.

The process of doctoral socialization is developmental and dynamic, occurring through a series of overlapping stages (Tinto, 1993; Lovitts, 2001; Weidman et al., 2001). According to Lovitts's four-stage model, during the prior and anticipatory socialization stage (preadmission), students select a doctoral program and develop initial expectations about academic and social aspects of doctoral experiences. The entry and adjustment stage (the first year) is characterized by the students transitioning from being outsiders to insiders in their chosen programs and research communities. In many biology programs, students are expected to begin their course work during this stage, and they are also required to rotate through several laboratories to identify a match with a faculty member to serve as a long-term mentor and research supervisor (Maher et al., 2018). In the development of competence stage (the second year through to the attainment of candidacy status), students are required to complete the course work and qualifying examinations. At the same time, they are involved in different research projects in their laboratories, and some of these students are also assigned to teach undergraduate courses. Finally, the research stage (completion of dissertation) requires students to finish their dissertations and to prepare for their professional careers after graduation. Although doctoral students' training experiences need to be understood within the unique context of each stage, the early periods in socialization are especially important, due to their relatively stronger influence on critical doctoral out- comes. For instance, the highest rate of attrition occurs during the first 2 years of doctoral study (Nerad and Miller, 1996). Studies report that this early attrition is largely caused by unfavorable socialization experiences, such as mismatches between prior expectations and reality in doctoral life (Golde, 1998; Lovitts, 2001), problematic advising relationships (Maher et al., 2018), and low levels of academic and social interactions with others (Tinto, 1993).

\section{Student-Faculty and Student-Peer Interactions}

Faculty and peers have been considered the two most important socialization agents that shape students' daily experiences and affect desired doctoral outcomes (Gardner, 2010; Weidman, 2010; Flores-Scott and Nerad, 2012). Doctoral students' interactions with faculty can come in different forms. For example, Weidman and Stein (2003) suggest four types of graduate student-faculty interactions: social, academic (field-related), intellectual (non-field related), and personal. Further, research on doctoral advising and mentoring has identified specific roles of faculty members (e.g., Tenenbaum et al., 2001; Zhao et al., 2007; Barnes and Austin, 2009; Noy and Ray, 2012). For example, Zhao et al. (2007) found four distinct, student-reported behaviors of faculty advisors that capture both positive and negative aspects of the advising relationship: academic advising, personal interactions, career development, and cheap labor (i.e., treating students as a cheap source of labor to advance their research). These researchers further found that students in the biological sciences reported lower levels of perceived academic advising and personal interactions, but higher levels of career development and cheap labor, compared with their peers in the humanities and social sciences.

While the roles of faculty and faculty-student relationships during doctoral training have been well documented in the literature, surprisingly little attention has been paid to the role of peers and peer relationships (Flores-Scott and Nerad, 2012; Littlefield et al., 2015; Meschitti, 2018). This is perhaps because much of the existing literature has examined doctoral training through a traditional cognitive apprenticeship model of faculty-to-student mentorship (Flores-Scott and Nerad, 2012; Maher et al., 2013). However, graduate students tend to interact more frequently with their peers than they do with faculty (Weidman and Stein, 2003), and this may be especially true for doctoral students in lab sciences, where doctoral training happens within collaborative laboratory settings.

Further, the nature of doctoral students' relationships with their peers differ from those with their faculty (Boud and Lee, 2005; Flores-Scott and Nerad, 2012). Flores-Scott and Nerad (2012) pointed out that while the faculty-student relationship is likely to be vertical in nature (i.e., faculty advisors transfer their knowledge and skills to their students), peers are more likely to have a comentoring relationship, in which they exchange specific knowledge and feedback with one another. In a similar vein, recent models of graduate mentorship in laboratory contexts suggests that "cascade mentoring," in which graduate students receive substantial mentorship from senior peers and postdoctoral researchers has become a vital aspect of doctoral training (Golde et al., 2009). Within the context of these interactions, it is important to examine both faculty and peer interactions together to more fully capture doctoral students' socialization processes and related outcomes. 


\section{Demographic Determinants of Student Interactions}

Beyond the generic role of student, sociodemographic differences also play a role in shaping socialization interactions (Twale et al., 2016). Studies reveal patterns in how gender can shape the ways graduate students interact with faculty (e.g., Schroeder and Mynatt, 1993, 1999; Seagram et al., 1998; Nettles and Millett, 2006; Zhao et al., 2007; Ruud et al., 2018). In fact, Noy and Ray (2012) found that female students tend to report more affective and instrumental support relative to their male counterparts, although they posit that this may be due to the nature of how females are socialized to form emotional connections, which may lead them to actively seek out "secondary advisors who take interest in their personal lives" (p. 901). With regard to peer interactions, Sallee's (2011) study on doctoral students in engineering documents a gendered socialization process that privileges masculine values and is characterized by peer competition and hierarchies. Further, Sallee found that sexist comments from male students create a hostile peer environment for female students. However, gender differences in peer interactions among doctoral students are still poorly understood, indicating a need for further investigations.

Racial/ethnic disparities in student interactions with faculty and peers have also been documented (Taylor and Antony, 2000; Johnson-Bailey et al., 2009; Gildersleeve et al., 2011; Twale et al., 2016). For example, Black and Latinx doctoral students report that their relationships with their advisors are often constrained by race (Gildersleeve et al., 2011). Further, research reveals that students of color report isolation from and strained relationships with peers that result from pervasive discrimination in their programs (Johnson-Bailey et al., 2009). While Taylor and Antony (2000, p. 193) found that interactions with "like-minded peers helped mitigate social and intellectual isolation" among African-American doctoral students, a lack of racial/ethnic diversity in doctoral programs may leave students of color with limited opportunities to develop supportive and mentoring relationships with their fellow graduate students (Daniel, 2007).

Research has also documented how doctoral students interact and socialize with faculty and peers differently based on international student status (e.g., Rose, 2005; Sato and Hodge, 2009; Le and Gardner, 2010; Curtin et al., 2013; Zhang, 2016; Takashiro, 2017; Roksa et al., 2018). Studies reveal that international doctoral students tend to place great importance on their relationships with their advisors (Le and Gardner, 2010; Takashiro, 2017) and have a greater preference for faculty mentors who are "interpersonally involved" in their lives, relative to their domestic peers (Rose, 2005, p. 74). Yet, they tend to report relatively less positive socialization experiences with faculty (Roksa et al., 2018). In addition, their relationships with faculty tend to be centered around academics and relatively less personal in nature (Sato and Hodge, 2009; Takashiro, 2017). Further, similar to the patterns for students of color, international students report greater isolation from peers and more negative peer relationships relative to their domestic counterparts (Le and Gardner, 2010; Roksa et al., 2018). According to Sato and Hodge's (2009) study, Asian international doctoral students have difficulty building social interactions with their white peers, apparently due to language barriers and cultural differences. However, their relationships with other Asian international students within their doctoral programs are quite strong and positive both academically and socially.

\section{Outcomes of Socialization}

Within the socialization literature, the most frequently examined outcomes (dependent variables) include persistence (Golde, 1998, 2000, 2005; Lovitts, 2001; Maher et al., 2018), satisfaction with advisor (Zhao et al., 2007; Lunsford, 2012), and publication outcomes (Paglis et al., 2006; Feldon et al., 2017a). Surprisingly few studies examine individual students' research skills as a key outcome of their faculty and peer interactions (but see Feldon et al., 2016, 2017b). While publication data may also reflect students' abilities to conduct research, they are still limited in their capacity to measure individual students' research skills, given the impacts of coauthors, advisors, reviewers, and editors on the final product (Feldon et al., 2010). Further, given that many students are unlikely to publish journal articles during their first year of doctoral study, publication data may have limited value for assessing variations in students' research skills. The current study, therefore, uses students' sole-authored research proposals or reports of empirical findings collected before input from faculty advisors or editors to assess their abilities in various aspects of research skill.

In addition, previous research has also paid relatively less attention to affective or psychosocial outcomes that can be influenced by students' faculty and peer interactions. However, several empirical studies have confirmed that doctoral students' positive and supportive relationships with their advisors lead to increased research self-efficacy (Paglis et al., 2006), a better sense of belonging in graduate school (Curtin et al., 2013), a higher level of academic career aspirations (Curtin et al., 2016), and scholarly productivity (Paglis et al., 2006). Moreover, in her study of first-year doctoral student attrition, Golde (1998, p. 56) suggested the four primary tasks of early doctoral socialization. These tasks include 1) developing intellectual competence ("Can I do this?"); 2) facing the realities of life as a doctoral student ("Do I want to be a graduate student?"); 3) learning about the career path that one is pursuing ("Do I want to do this work?"); and 4) integrating oneself into the chosen department or research community ("Do I belong here?"). Consequently, in this study, we examine whether student interaction profiles among first-year doctoral students predict a variety of affective or psychosocial outcomes, including student satisfaction with academic development, goal commitment to degree completion, interest in a future faculty career, and research self-efficacy.

\section{METHODS}

The existing literature on student-faculty and student-peer interactions among doctoral students relies heavily on qualitative research, often with small sample sizes (e.g., Golde, 1998, 2000; Gardner, 2010; Flores, 2011; Meschitti, 2018). Among the quantitative studies that do exist, researchers have often employed variable-centered approaches (e.g., Weidman and Stein, 2003; Zhao et al., 2007; Noy and Ray, 2012). Because variable-centered approaches (e.g., regression analysis) primarily concern the relationships among specific constructs of interest across a whole sample examined, they overshadow individual heterogeneities within a sample, making it difficult to identify patterns in how individuals are socialized. In 
contrast, person-centered approaches (e.g., cluster analysis, latent class analysis) enable researchers to identify meaningful subsets of students based on distinct combinations on a set of constructs of interest (Muthén and Muthén, 2000).

Given that socialization theories have been criticized for their unifying or monolithic nature (Gardner, 2007), these person-centered analyses may shed new light on how individual doctoral students differ from one another in terms of how they interact with their faculty and peers simultaneously. In addition, from a practical point of view, the findings from these types of analyses can provide useful information about specific support or interventions to meet the needs of unique groups of students (Lanza and Rhoades, 2013). The present study, therefore, attempted to apply a person-centered technique to examine the joint occurrence of different forms of faculty and peer interactions within the sample of doctoral biology students. Accordingly, we address the following research questions:

1. What socialization profiles emerge as a function of first-year PhD students' interactions with faculty and student peers?

2. Do demographic characteristics of first-year PhD students predict the likelihood of membership within a socialization profile?

3. Does membership within socialization profiles differentially predict outcomes typically associated with socialization?

\section{Participants}

This study was part of a larger research project examining developmental trajectories among doctoral students in the biological sciences over 4 years. The initially recruited cohort consisted of 336 doctoral students in laboratory-based biology (e.g., cellular, molecular, genetic biology) who began their degree programs in the Fall of 2014. The participants attended one of 53 researchoriented universities or institutions in the United States, with an average of $6.34(\mathrm{SD}=5.69$, range $=1-24)$ participants per institution. Based on the Carnegie Classification, these universities were primarily classified as R1 (highest research activity; 79.2\%), followed by R2 (higher research activity; $13.2 \%$ ), and other $(7.5 \%)$. Overall, the vast majority $(88 \%)$ of our sample belonged to R1 universities. In addition, most participants were assigned to research laboratories where they work collaboratively with research team members comprising a primary faculty advisor, other faculty members or postdoctoral researchers, and fellow students. During the first year of doctoral training, they were required to rotate through multiple laboratories, not only to acquire research-related knowledge and skills, but also to determine a permanent lab in which they would conduct their dissertation project.

Of the 336 participating students, 200 (59.5\%) were female, 132 (39.3\%) were male, and four (1.2\%) withheld gender data (i.e., did not respond to the item). Sixty-six (19.6\%) participants were international students, 266 (79.2\%) were domestic, and four $(1.2 \%)$ were unknown. Our sample also included $200(59.5 \%)$ white students, 71 (21.1\%) Asian students, 26 (7.7\%) Latina/o/x students, 21 (6.3\%) Black students, two (0.6\%) Native Hawaiian or other Pacific Islander/American/ Alaskan students, 10 (2.9\%) students from other racial/ethnic groups, and six (1.8\%) who had missing racial/ethnic data. In this study, underrepresented minority (URM) students ( $n=59$; $17.5 \%$ ) were identified as those who did not identify as white or Asian. In other words, URM students included those who selected one or more Black, Latina/o/x, Native Hawaiian or other Pacific Islander/American/Alaskan, or "other" racial/ ethnic identity. The demographics of our sample generally align with those of the sample used in a nationally representative study of doctoral students (Survey of Graduate Students and Postdoctorates in Science and Engineering; National Science Foundation [NSF], 2017).

\section{Procedures}

Participants were initially recruited via email from 203 U.S. universities or institutions offering $\mathrm{PhD}$ programs in the biological sciences. Those who responded to the recruitment emails were screened for their study eligibility and then asked to sign informed consent forms. Participants were required to complete self-reported surveys regarding their doctoral experiences and submit their sole-authored research work (e.g., written research reports or proposal). Participants received $\$ 400$ annually as a participation incentive. The current study uses data drawn from the first-year survey and performance (e.g. research skills and productivity). These survey and performance data were obtained in the Spring and Summer of 2015, respectively.

\section{Measures}

Student-Faculty and Student-Peer Interactions. Student interactions were measured using an eight-item scale assessing the doctoral socialization experience (Weidman and Stein, 2003). Participants were asked to indicate whether they had interacted with a professor or a peer in their departments in four specific ways ( $0=$ no, $1=$ yes), such as social conversation, discussion about field-relevant topics, discussion about other topics of academic interest, and conversation about personal issues.

Academic Development. Students' perceived academic development measured the degree to which they were satisfied with their scholarly experience in their doctoral programs (three items; e.g., "My academic experience has had a positive influence on my intellectual growth and interest in ideas."). The internal consistency of the scale was obtained using McDonald's coefficient omega, $\omega=0.86$. This scale was taken from Nora and Cabrera's (1996) instrument, and responses were rated on a three-point Likert scale $(1=$ disagree, 3 = agree $)$.

Institutional Commitment. Institutional commitment (Nora and Cabrera, 1996) was measured by asking about the degree to which students had confidence in the institutions they chose (three items; e.g., "I am certain this institution is the right choice for me."; $\omega=0.87)$. Responses were given on a threepoint Likert scale ( 1 = disagree, 3 = agree).

Degree Completion. Degree completion (Nora and Cabrera, 1996) was measured by asking about the extent to which students felt the importance of completing their doctoral degrees (three items; e.g., "It is important for me to finish my program of studies."; $\omega=0.91$ ). Responses were provided on a three-point Likert scale ( 1 = disagree, 3 = agree).

Sense of Belonging. Sense of belonging was measured using a three-item scale taken from Bollen and Hoyle's (1990) study. Students also rated their subjective sense of belonging in their 
laboratories on a 11-point Likert scale (strongly disagree to strongly agree). Sample items included "I feel a sense of belonging to my lab/research group." and "I see myself as part of the lab/research group community." The internal consistency coefficient of reliability for the scale was $\omega=0.96$.

Interest in Faculty Career. A single item was used to ask students about their interest in a faculty career on a three-point Likert scale ( $1=$ not at all, $3=$ definitely).

Research Self-Efficacy. Students' research self-efficacy was measured using Kardash's (2000) instrument assessing individual competencies for specific research skills (10 items; $\omega=$ 0.90). Sample items included "To what extent do you feel you can identify a specific question for investigation based on the research in your field?" and "To what extent do you feel you can interpret data by relating results to the original hypothesis?" Participants responded on a five-point Likert scale $(1=$ not at all, 5 = a great deal).

Research Skills. In addition to these affective outcomes, we also included cognitive outcomes likely associated with students' interactions. Specifically, we assessed students' research skills using their sole-authored work products (e.g., research report, conference paper). These written papers were scored by two qualified raters based on a rubric that assesses 13 different essential research skills (e.g., addressing testable hypotheses, collecting data, and identifying significances of the study) by specific criteria. This rubric has been established and validated in previous studies with graduate students (e.g., Feldon et al., 2011). The interrater reliability using intraclass correlations (two-way, random effects) for each of the 13 research skills ranged between 0.78 and 0.95 .

Research Productivity. We also measured students' research productivity using their publication records. Participants indicated (no $=0$, yes $=1$ ) whether they have published any journal articles or abstracts or presented papers at conferences since they began their doctoral studies. The accuracy of these responses was validated using the citation information.

Table 1 presents the descriptive statistics and correlations for all of the variables used in this study.

\section{Data Analysis}

In our first research question, we focus on identifying the different patterns in peer and faculty interactions among doctoral students. To investigate this, we used latent class analysis (LCA). LCA is a person-oriented statistical analysis intended to identify meaningful but unobserved subgroups among individuals on the basis of their patterns of behaviors or characteristics (Collins and Lanza, 2010). LCA offers some advantages over other commonly used clustering approaches (Magidson and Vermunt, 2002). In $k$-means cluster analysis, for example, diagnostic information is not available. However, LCA provides various diagnostic statistics to determine the most appropriate number of distinct classes. In addition, LCA classifies individuals into classes using model-based posterior membership probabilities.

To select the best-fitting latent class model, we compared models with two, three, four, five, and six latent classes using the following information criteria (ICs): Akaike's information criterion (AIC; Akaike, 1987), the Bayesian information criterion (BIC; Schwartz, 1978), and the sample size-adjusted BIC (aBIC). The model with the lowest AIC, BIC, or aBIC value is generally preferred, but the BIC is often considered the best indicator for determining the number of classes (Nylund et al., 2007). In addition to the ICs, the Vuong-Lo-Mendell-Rubin (VLMR) likelihood ratio test (Vuong, 1989) and Lo-MendellRubin (LMR) likelihood ratio test (Lo et al., 2001) assessed whether a model with $G$ latent classes showed a significantly better fit than a model with $G-1$ latent classes. Further, the entropy value (Celeux and Soromenho, 1996; i.e., indicator of overall quality of classification) and the average class assignment probabilities were also considered.

Following the selected LCA model, each individual was assigned to one class based on his or her maximum class assignment probability. The assigned classes were used as categorical variables for subsequent analyses. Next, we performed a series of multinomial logistic regression analyses to address our second research question, which considers the associations between the LCA designations and students' demographic characteristics. Finally, for our third research question, which examines the connections between different interaction classifications and eight student outcomes, we conducted a series of multivariate regression analyses, except for research productivity. We used logistic regressions to predict research productivity by students' interaction patterns.

We performed all analyses in Mplus v. 8.1 (Muthén and Muthén, 1998-2017). Missing data were handled using the full information maximum likelihood technique. To account for individual students nested within universities, all analyses were done within a multilevel modeling framework using the Mplus command: TYPE = complex.

\section{RESULTS \\ Latent Classes: Patterns of Student-Faculty and Student-Peer Interactions}

We performed LCAs to identify unique classes of doctoral students based on the nature of their interactions with faculty and peers. To determine the best-fitting latent class model, we compared models with one to six latent classes based on different criteria (Table 2). The values for the AIC, BIC, and aBIC were all the smallest with a four-class solution, suggesting that a model with four classes had the best fit for the data. In addition, the VLMR and LMR results favored the four-class model over the three-class model $(p<0.001)$. The five-class model also did not provide a significantly better fit than the four-class model according to the VLMR and LMR tests $(p=0.56)$, supporting the four-class model as the best solution. Further, the four-class model also had a relatively high entropy value (i.e., close to $1 ; E=0.81$ ), suggesting that the classes are clearly distinguishable from one another. Finally, the average class assignment probabilities for students belonging to each of the four classes were quite high (0.82-0.95), which indicates that students were classified into their most likely class with high certainty.

Figure 1 shows the four types of doctoral students' interactions with faculty and peers based on the LCA results. Students in class 1 showed a pattern of very or relatively high response probabilities for the answer "yes" for all eight faculty-peer interaction items. That is, students in this class were more likely to have one or more peers and professors to interact with in 


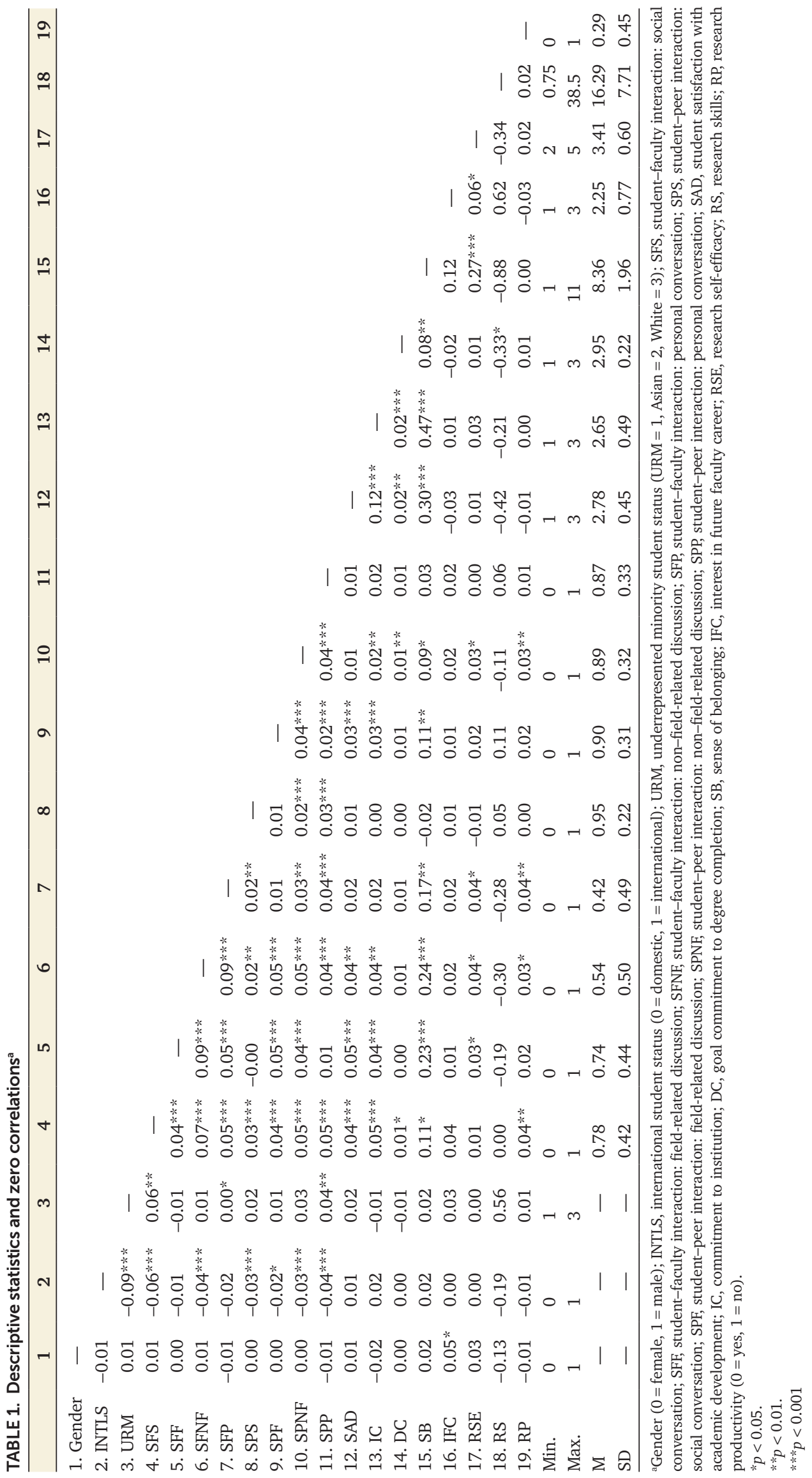


TABLE 2. Fit statistics with latent class models ${ }^{\mathrm{a}}$

\begin{tabular}{|c|c|c|c|c|c|c|c|c|}
\hline No. of classes & AIC & BIC & aBIC & Log likelihood & No. of $\mathrm{fp}^{\mathrm{b}}$ & VLMR & LMR & Entropy \\
\hline 1 & 2452.10 & 2482.37 & 2456.99 & -1218.05 & 8 & & & \\
\hline 2 & 2163.06 & 2227.38 & 2173.46 & -1064.53 & 17 & $<0.001$ & $<0.001$ & 0.78 \\
\hline 3 & 2113.61 & 2211.99 & 2129.52 & -1030.81 & 26 & 0.19 & 0.20 & 0.74 \\
\hline 4 & 2078.50 & 2210.93 & 2099.91 & -1004.25 & 35 & $<0.05$ & $<0.05$ & 0.81 \\
\hline 5 & 2080.02 & 2246.51 & 2106.94 & -996.01 & 44 & 0.55 & 0.56 & 0.85 \\
\hline 6 & 2083.97 & 2284.52 & 2116.40 & -988.99 & 53 & 0.48 & 0.46 & 0.86 \\
\hline
\end{tabular}

astatistics for the selected LCA model are in bold type.

${ }^{b}$ No. of fp, number of free parameters.

diverse ways in their departments. We therefore named this class Faculty and Peer: Academic and Social/Personal, with $42.2 \%$ ( $n=137$ ) of the sample belonging to this group.

Students in class 2, on the other hand, showed high response probabilities for the answer "yes" for the four peer interaction items, but relatively lower probabilities for faculty interaction items. We thus labeled this class Peer Only: Academic and Social/Personal ( $n=134 ; 41.2 \%$ ). Students in this class were more likely to interact with peers in their departments in multiple ways (e.g., academically, socially, and personally) and less likely to interact with faculty in the same ways.

Students in classes 3 and 4 showed different patterns of conditional response probability. Class 3 included students who interact frequently with their peers, but only in social/ personal conversation. We labeled this class as Peer Only: Social/Personal ( $n=27 ; 8.3 \%)$.

Students in class 4 , on the other hand, indicated academic and field-related interactions with faculty; they showed very high or relatively high response probabilities for the answer "yes" for the items asking if they had any peer or professor with whom to discuss field-related topics. However, their response probabilities for the answer "yes" for the other six items were relatively low or moderate. We thus categorized this class as Faculty and Peer: Field-Related Academic $(n=27 ; 8.3 \%)$.

\section{Differences in Interaction Types by Sociodemographic Characteristics}

Descriptive statistics for distributions of each sociodemographic group within latent classes are summarized in Table 3 and Figure 2. Few differences emerged by gender. Among both female and male students, Faculty and Peer: Academic and Social/Personal, was the largest class (43 and 42\%, respectively), followed by the Peer Only: Academic and Social/ Personal class (42 and 40\%, respectively). The remaining two interaction classes accounted for a relatively small proportion of each gender group. This trend was also the case for domestic, white, and URM demographic groups, respectively. A particularly small proportion of white students fell into the Faculty and Peer: Field-Related Academic class (1\%).

Very different patterns were observed among international and Asian demographic groups. For both groups, the proportion of the Peer Only: Academic and Social/Personal class was the largest (37\% for both groups), and the Faculty and Peer: Field-Related Academic class also accounted for a considerable proportion (27\% for both groups).

To further examine how these latent classes might differ as a function of students' demographic characteristics, we also ran multinomial logistic regression analyses (see Table 4). These findings revealed no significant gender differences. However, international student status significantly predicted interaction patterns. Compared with domestic students, international students were significantly more likely to belong to the Peer Only: Social/Personal (odds ratio $=4.01$ ) and Faculty and Peer: Field-Related Academic (odds ratio $=6.20$ ) classes relative to the Faculty and Peer: Academic and
FIGURE 1. Four types of doctoral students' interactions with faculty and peers based on the LCA results. 
TABLE 3. Interaction class distributions of each demographic group

\begin{tabular}{|c|c|c|c|c|}
\hline & $\begin{array}{l}\text { Class 1: Faculty and } \\
\text { Peer: Academic and } \\
\text { Social/Personal } \\
(n=135,42 \%)\end{array}$ & $\begin{array}{c}\text { Class 2: Peer Only: } \\
\text { Academic and Social/ } \\
\text { Personal }(n=132,41 \%)\end{array}$ & $\begin{array}{l}\text { Class 3: Peer Only: } \\
\text { Social/Personal } \\
(n=27,9 \%)\end{array}$ & $\begin{array}{c}\text { Class 4: Faculty and } \\
\text { Peer: Field-Related } \\
\text { Academic }(n=26,8 \%)\end{array}$ \\
\hline Female $(n=193)$ & $82(43 \%)$ & $81(42 \%)$ & $16(8 \%)$ & $14(7 \%)$ \\
\hline Male $(n=127)$ & $53(42 \%)$ & $51(40 \%)$ & $11(9 \%)$ & $12(9 \%)$ \\
\hline International $(n=62)$ & $13(21 \%)$ & $23(37 \%)$ & $9(15 \%)$ & $17(27 \%)$ \\
\hline \multicolumn{5}{|l|}{ URM student status } \\
\hline White $(n=195)$ & $92(47 \%)$ & $87(45 \%)$ & $14(7 \%)$ & $2(1 \%)$ \\
\hline Asian $(n=67)$ & $17(25 \%)$ & $25(37 \%)$ & 7 (11\%) & $18(27 \%)$ \\
\hline URM $(n=58)$ & $26(45 \%)$ & $20(35 \%)$ & $6(10 \%)$ & $6(10 \%)$ \\
\hline
\end{tabular}

${ }^{a}$ The percentages across rows are based on the first-column values.

Social/Personal class. In addition, international students were also more likely to be in the Faculty and Peer: Field-Related Academic class rather than the Peer Only: Academic and Social/Personal class (odds ratio $=3.38$ ). In general, domestic students tended to have a wider range of interactions (e.g., academic, social, and personal), while international students' interactions were limited to specific types (e.g., field-relevant conversations, social/personal relationships with peers), revealing distinct inequities in the socialization experiences of doctoral students.

Analysis by race/ethnicity yielded similar patterns of inequity. Relative to their white counterparts, Asian students were more likely to fall into the Faculty and Peer: Field-Related Academic class than the other three classes. More modest differences emerged between white and URM students. Namely, URM students were more likely to be in the Faculty and Peer: Field-Related Academic class rather than the Faculty and Peer: Academic and Social/Personal (odds ratio $=8.12$ ) and Peer Only: Academic and Social/Personal (odds ratio $=10.65$ ) classes. No significant differences were observed between Asian and URM students.

\section{Associations between Interaction Types and Doctoral Outcomes}

We also explored the connections between different latent classes in faculty and peer interactions to a range of doctoral outcomes using multivariate (or logistic) regression analyses. These outcomes include 1) student satisfaction with academic development, 2) commitment to institution, 3) goal commitment to degree completion, 4) sense of belonging, 5) interest in future faculty career, 6) research self-efficacy, 7) research skills, and 8) research productivity.

Before we performed a series of multivariate (or logistic) regression analyses, we computed the descriptive statistics for all variables (see Table 5). Compared with the other three interaction classes, students in the Faculty and Peer: Academic and Social/Personal class had the highest scores on all eight outcome variables. In contrast, students in the Peer Only: Social/ Personal class had the lowest scores on all seven variables, except for research skills. In addition, interesting patterns were found in students in the Faculty and Peer: Field-Related Academic class. While these students had relatively higher scores on satisfaction with academic development, institutional commitment, sense of belonging, and research productivity, their scores on research self-efficacy and research skills were the lowest among the four interaction classes.

Table 6 presents the results of the multivariate (or logistic) regression analyses predicting each of the outcome variables by the four interaction classes. We found significant differences among the interaction classes in four outcomes out of eight, including satisfaction with academic development, institutional commitment, sense of belonging to research community or lab, and research productivity. Specifically, students in the Faculty and Peer: Academic and Social/Personal were significantly more likely to report higher scores on satisfaction with academic development relative to those in the Peer Only: Academic and Social/Personal or Peer Only: Social/Personal classes. In

FIGURE 2. Interaction class distributions of each demographic group. 
TABLE 4. Results of multinomial logistic regressions predicting interaction classes by demographics ${ }^{\mathrm{a}}$

\begin{tabular}{|c|c|c|c|c|c|c|c|c|c|}
\hline & \multicolumn{3}{|c|}{ Class 2 vs. 1} & \multicolumn{3}{|c|}{ Class 3 vs. 1} & \multicolumn{3}{|c|}{ Class 4 vs. 1} \\
\hline & B (SE) & $p$ & OR & B (SE) & $p$ & OR & B (SE) & $p$ & OR \\
\hline Male vs. female & $-0.001(0.322)$ & 0.998 & 0.999 & $0.133(0.375)$ & 0.723 & 1.142 & $0.700(0.533)$ & 0.189 & 2.014 \\
\hline International vs. domestic & 0.607 (0.509) & 0.233 & 1.835 & $1.388(0.660)$ & $0.035 *$ & 4.006 & $1.824(0.546)$ & $0.001 * *$ & 6.199 \\
\hline Asian vs. white & $0.204(0.506)$ & 0.687 & 1.226 & $0.379(0.567)$ & 0.504 & 1.460 & $3.129(0.934)$ & $0.001 * *$ & 22.843 \\
\hline URM vs. white & $-0.270(0.331)$ & 0.414 & 0.763 & $0.222(0.552)$ & 0.687 & 1.249 & $2.095(0.988)$ & $0.034 *$ & 8.124 \\
\hline \multirow[t]{3}{*}{ Asian vs. URM } & $0.474(0.537)$ & 0.377 & 1.607 & $0.156(0.664)$ & 0.814 & 1.169 & $1.034(0.679)$ & 0.128 & 2.812 \\
\hline & \multicolumn{3}{|c|}{ Class 3 vs. 2} & \multicolumn{3}{|c|}{ Class 4 vs. 2} & \multicolumn{3}{|c|}{ Class 4 vs. 3} \\
\hline & B (SE) & $p$ & OR & B (SE) & $p$ & OR & $\mathrm{B}(\mathrm{SE})$ & $p$ & OR \\
\hline Male vs. female & $0.134(0.365)$ & 0.714 & 1.143 & $0.701(0.522)$ & 0.180 & 2.016 & $0.567(0.542)$ & 0.296 & 1.763 \\
\hline International vs. domestic & $0.781(0.570)$ & 0.171 & 2.183 & $1.217(0.493)$ & $0.013 *$ & 3.377 & $0.436(0.542)$ & 0.421 & 1.547 \\
\hline Asian vs. white & $0.175(0.547)$ & 0.749 & 1.191 & $2.925(0.866)$ & $0.001 * *$ & 18.632 & $2.750(0.920)$ & $0.003 * *$ & 15.643 \\
\hline URM vs. white & $0.493(0.478)$ & 0.303 & 1.637 & $2.365(0.837)$ & $0.005^{* *}$ & 10.647 & $1.872(0.996)$ & 0.060 & 6.504 \\
\hline Asian vs. URM & $-0.318(0.542)$ & 0.557 & 0.728 & $0.560(0.486)$ & 0.250 & 1.750 & $0.878(0.521)$ & 0.092 & 2.405 \\
\hline
\end{tabular}

a OR, Odds ratio. Class 1: Faculty and Peer: Academic and Social/Personal; class 2: Peer Only: Academic and Social/Personal; class 3: Peer Only: Social/Personal; class 4: Faculty and Peer: Field-Related Academic; B, unstandardized coefficient; SE, standard error.

${ }^{*} p<0.05$.

$* * p<0.01$

addition, students in the Peer Only: Academic and Social/ Personal class reported a significantly higher level of perceived academic development than those in the Peer Only: Social/ Personal class. These results indicate that students who interacted with both faculty and peers were more likely to be satisfied with their academic development at the chosen institutions compared with students whose interactions occurred mostly with peers. Further, students interacting with their peers in more diverse ways (e.g., academically, socially, and personally) were more likely to feel satisfied with their academic growth compared with those who had social and personal relationships only with their peers. Similar patterns were found in the outcomes, institutional commitment, sense of belonging variables, and research productivity. That is, students who interacted with both faculty and peers in a more inclusive way were significantly more likely to feel confident in their institutional choice, to feel assured of their belonging to the research group, and to have more publications relative to their fellow students who mostly interacted with peers rather than faculty. In addition, students whose interactions with their peers were more inclusive tended to be significantly more certain of their selection of the institution compared with those who interacted with their peers mostly socially and personally. Finally, our results also revealed that students in the Faculty and Peer: Field-Related
Academic class were significantly more likely to report a higher level of institutional commitment than those in the Peer Only: Social/Personal class. In other words, although a student's interaction was restricted in a certain way, if it was field-related and occurred with both faculty and peers, such interaction was positively associated with his or her commitment to the chosen institution compared with peer interactions that happened socially and personally only.

\section{DISCUSSION}

In this study, we identified four distinct classes of doctoral socialization patterns with faculty and students. Across these latent classes, specific demographic groups were significantly more likely to be included in those with lower levels of engagement. Specifically, international, Asian, and URM students were disproportionately likely to belong to the Faculty and Peer: Field-Related Academic class compared with other latent classes. These findings indicate that, while both groups were successful in engaging both faculty and other students in scholarly interactions, their experiences were constrained to that mode of socialization and did not reflect broader interactions, consistent with previous findings (Golde, 2000).

It is notable that URM students were generally as likely as their white counterparts to belong to the Faculty and Peer:

TABLE 5. Descriptive statistics for student outcomes by interaction class ${ }^{\mathrm{a}}$

\begin{tabular}{lcccc}
\hline & Class 1 M (SD) & Class 2 M (SD) & Class 3 M (SD) & Class 4 M (SD) \\
\hline Academic development & $2.87(0.30)$ & $2.77(0.47)$ & $2.46(0.64)$ & $2.74(0.51)$ \\
Institutional commitment & $2.75(0.45)$ & $2.62(0.47)$ & $2.29(0.62)$ & $2.68(0.42)$ \\
Degree completion & $2.96(0.18)$ & $2.95(0.20)$ & $2.86(0.38)$ & $2.91(0.25)$ \\
Sense of belonging & $8.79(1.82)$ & $8.08(1.89)$ & $7.51(2.24)$ & $8.35(2.17)$ \\
Interest in faculty career & $2.36(0.80)$ & $2.18(0.79)$ & $1.99(0.92)$ & $2.11(0.71)$ \\
Research self-efficacy & $3.46(0.59)$ & $3.38(0.60)$ & $3.32(0.67)$ & $16.35(9.09)$ \\
Research skills & $16.54(8.30)$ & $16.24(7.14)$ & $0.08(0.28)$ & $15.39(6.87)$ \\
Research productivity & $0.38(0.49)$ & $0.25(0.43)$ & $0.21(0.41)$ & \\
\hline
\end{tabular}

aClass 1: Faculty and Peer: Academic and Social/Personal; class 2: Peer Only: Academic and Social/Personal; class 3: Peer Only: Social/Personal; class 4: Faculty and Peer: Field-Related Academic. 
TABLE 6. Results of multivariate regressions predicting student outcomes by interaction class ${ }^{a}$

\begin{tabular}{|c|c|c|c|c|c|c|}
\hline & \multicolumn{2}{|c|}{ Academic development } & \multicolumn{2}{|c|}{ Institutional commitment } & \multicolumn{2}{|c|}{ Degree completion } \\
\hline & B (SE) & $p$ & B (SE) & $p$ & B (SE) & $p$ \\
\hline Class 1 vs. 4 & $0.133(0.103)$ & 0.198 & $0.073(0.116)$ & 0.530 & $0.048(0.050)$ & 0.343 \\
\hline Class 2 vs. 4 & $0.025(0.110)$ & 0.824 & $-0.060(0.112)$ & 0.596 & $0.039(0.050)$ & 0.436 \\
\hline Class 3 vs. 4 & $-0.290(0.155)$ & 0.061 & $-0.405(0.146)$ & $0.006 * *$ & $-0.068(0.090)$ & 0.448 \\
\hline Class 1 vs. 3 & $0.423(0.154)$ & $0.006 * *$ & $0.477(0.141)$ & $0.001 * *$ & $0.116(0.075)$ & 0.121 \\
\hline Class 2 vs. 3 & $0.314(0.144)$ & $0.029 *$ & $0.345(0.134)$ & $0.010^{*}$ & $0.107(0.073)$ & 0.144 \\
\hline \multirow[t]{3}{*}{ Class 1 vs. 2} & $0.108(0.046)$ & $0.017^{*}$ & $0.132(0.059)$ & $0.024^{*}$ & $0.009(0.027)$ & 0.753 \\
\hline & \multicolumn{2}{|c|}{ Sense of belonging } & \multicolumn{2}{|c|}{ Interest in faculty career } & \multicolumn{2}{|c|}{ Research self-efficacy } \\
\hline & B (SE) & $p$ & B (SE) & $p$ & B (SE) & $p$ \\
\hline Class 1 vs. 4 & $0.446(0.389)$ & 0.252 & $0.249(0.176)$ & 0.158 & $0.138(0.130)$ & 0.289 \\
\hline Class 2 vs. 4 & $-0.263(0.431)$ & 0.541 & $0.084(0.143)$ & 0.558 & $0.058(0.138)$ & 0.672 \\
\hline Class 3 vs. 4 & $-0.839(0.663)$ & 0.206 & $0.172(0.229)$ & 0.453 & $-0.004(0.159)$ & 0.981 \\
\hline Class 1 vs. 3 & $1.284(0.534)$ & $0.016^{*}$ & $0.077(0.168)$ & 0.648 & $0.141(0.158)$ & 0.372 \\
\hline Class 2 vs. 3 & $0.576(0.524)$ & 0.272 & $-0.088(0.170)$ & 0.604 & $0.062(0.146)$ & 0.672 \\
\hline \multirow[t]{3}{*}{ Class 1 vs. 2} & $0.709(0.275)$ & $0.010^{*}$ & $0.165(0.111)$ & 0.137 & $0.079(0.085)$ & 0.353 \\
\hline & \multicolumn{2}{|c|}{ Research skills } & \multicolumn{3}{|c|}{ Research productivity } & \\
\hline & B (SE) & $p$ & B (SE) & $p$ & OR & \\
\hline Class 1 vs. 4 & $1.284(1.827)$ & 0.482 & $0.862(0.532)$ & 0.105 & 2.369 & \\
\hline Class 2 vs. 4 & $0.881(1.808)$ & 0.626 & $0.247(0.570)$ & 0.665 & 1.280 & \\
\hline Class 3 vs. 4 & $2.884(2.654)$ & 0.277 & $-1.016(0.810)$ & 0.209 & 0.362 & \\
\hline Class 1 vs. 3 & $-1.600(2.326)$ & 0.492 & $1.879(0.765)$ & $0.014^{*}$ & 6.545 & \\
\hline Class 2 vs. 3 & $-2.003(2.450)$ & 0.414 & $1.263(0.832)$ & 0.129 & 3.537 & \\
\hline Class 1 vs. 2 & $0.403(1.167)$ & 0.730 & $0.616(0.296)$ & $0.037^{*}$ & 1.851 & \\
\hline
\end{tabular}

aOR, Odds ratio. Class 1: Faculty and Peer: Academic and Social/Personal; class 2: Peer Only: Academic and Social/Personal; class 3: Peer Only: Social/Personal; class 4: Faculty and Peer: Field-Related Academic. For research productivity, logistic regressions analyses were performed; B, unstandardized coefficient; SE, standard error. ${ }^{*} p<0.05$.

$* * p<0.01$

Academic and Social/Personal class, which represents the highest levels and broadest range of socialization interactions. Thus, the restricted range of socialization for that group appears to involve interactions with other students that linked to personal and social modes. However, Asian and international students' overrepresentation in the Faculty and Peer: Field-Related Academic class stemmed from their underrepresentation in the broader modes of socialization with faculty that drove membership in the Faculty and Peer: Academic and Social/Personal class. As such, it is important to consider both faculty and peer interactions together rather than looking at a single socialization agent in isolation.

These trends highlight the discrepant experiences of multiple minority groups in the context of doctoral education in the biological sciences, consistent with previous studies (e.g., Taylor and Antony, 2000; Roksa et al., 2018). However, in contrast to other previous findings, there were no gender differences in socialization patterns. It is possible that these contrasting demographic findings reflect an overall level of representation in $\mathrm{PhD}$ programs. Females within the biological sciences account for degree attainment at a comparable (and slightly greater) proportion than men, but nonwhite students account for substantially lower proportions of degree attainment (NSF, 2015).

The associations between socialization and relevant outcomes, however, present a more mixed picture. Austin and McDaniels (2006, p. 400) define socialization as a "process of internalizing the expectations, standards, and norms of a given society, which includes learning the relevant skills, knowledge, habits, attitudes, and values of the group that one is joining." While membership in latent classes differentially predicted poorer affective and experiential outcomes in areas such as sense of belonging, satisfaction with academic development experiences, institutional commitment, and publication rate, it did not predict research skill, commitment to degree completion, research self-efficacy, or interest in a faculty career. These specific measures are important, because they map directly onto key elements and outcomes of the socialization process. According to Weidman and colleagues (Weidman et al., 2001; Twale et al., 2016), the central elements and outcomes of the socialization process are supposed to be knowledge acquisition (e.g., research skill), investment (e.g., commitment to degree), and involvement in university and professional communities (e.g., publication), forming the basis of scholarly identity (e.g., research self-efficacy, interest in faculty career). However, the absence of relationships between patterns of socialization and most of these outcomes raises important questions about the ability of the theory to account for findings beyond feelings of social connection themselves (i.e., sense of belonging, institutional commitment, satisfaction with academic experiences).

\section{Limitations}

There are several important limitations to consider when interpreting the current findings. First, our measure of peer and faculty interactions was based on simple yes/no responses, 
which hinders our ability to assess how individual students differ quantitatively or qualitatively in terms of a certain way of interaction. For example, there might be a student who had many productive conversations about his/her research with a faculty member and another student who experienced one very disappointing conversation during the same time period, something our measure cannot differentiate.

It is also important to note that demographic identities are not unitary in nature. Due to small sample sizes, we aggregated students into three racial groups (URM, white, and Asian/Asian American). Aggregating students in this way might have masked meaningful racial/ethnic differences that exist. Likewise, sample size prevented the exploration of intersectionality as a factor in predicting socialization class or outcomes. Thus, it is possible that there are gender differences entangled with racial/ethnic differences or differences for international students.

The present work also does not account for the demographics of faculty and peers or the extent to which faculty/advisors and students share or differ in their demographic characteristics. This is especially important when considering the experiences of female, URM, and international students, who may be more likely to experience negative interactions or bias from peers and faculty, which may in turn shape subsequent engagement with peers and faculty.

It should be also acknowledged that our findings are limited to our ability to make casually directional claims about the influence of students' socialization experiences on the study outcomes. Given that the self-reported data of this study were all obtained at one point in time and all analyses are fundamentally correlational in nature, we were not able to examine the casual relationship between patterns of student interactions and their socialization outcomes.

Finally, this study examined students' socialization patterns exclusively during the first year of doctoral study. These interactions likely evolve throughout graduate school—especially as students locate permanent faculty advisors and laboratories in which they will spend the remainder of their graduate careers. Thus, patterns may differ for more advanced doctoral students.

\section{Implications}

Our findings reveal distinct inequities in how doctoral students access socialization as a function of their racial/ethnic and international status during their first year. Despite the lack of direct impact on multiple outcomes of interest observed in this study, it is imperative that the field contend with these inequities for both ethical and practical reasons. Underrepresented populations often report different experiences of their environments than others (e.g., Byars-Winston, 2006; Byars-Winston et al., 2010; Jaeger et al., 2013; Griffin et al., 2015), highlighting differences in access to support, perceptions of climate, and career encouragement. Prior research suggests that faculty stereotypes and implicit biases about females and people of color may shape scientists' access to and quality of socialization experiences generally, and mentoring specifically (McCoy et al., 2015; Robinson et al., 2016; Williams et al., 2016). For example, African-American $\mathrm{PhD}$ students in the sciences have $61 \%$ lower odds of having a mentor and $71 \%$ lower odds of becoming a research assistant after 1 year of graduate study compared with their white peers (Millett and Nettles, 2006).
While the differences in experiences and outcomes we found may not directly affect competencies or scholarly productivity (i.e., students' abilities to do the jobs of faculty and research scientists), they do enhance or constrain essential access to professional opportunities and may shape interest and persistence in those careers over time. For example, prior research has found that interest in pursuing faculty careers at research-intensive universities differs substantially along demographic lines, with fewer females and individuals from historically underrepresented racial/ethnic groups remaining interested in becoming professors after doctoral and postdoctoral training (Gibbs and Griffin, 2013; Gibbs et al., 2014). Similarly, Estrada and colleagues (2011) found that the extent to which underrepresented racial/ethnic minority students identified as scientists and internalized values associated with science predicted persistence in science and intention to pursue science careers more effectively than self-efficacy measures. As such, efforts to mitigate unconscious bias among faculty and graduate students are vital to reduce the capacity of socialization experiences to curtail the professional opportunities afforded those whose skills and productivity otherwise warrant entry into desired academic and research positions.

\section{ACKNOWLEDGMENTS}

The authors gratefully acknowledge the support of the National Science Foundation (NSF). This material is based upon work supported under awards 1431234 and 1760894 . Any opinions, findings, and conclusions or recommendations expressed in this material are those of the authors and do not necessarily reflect the views of the NSF.

\section{REFERENCES}

Akaike, H. (1987). Factor analysis and AIC. Psychometrika, 52, 317-332.

Austin, A. E. (2002). Preparing the next generation of faculty: Graduate school as socialization to the academic career. Journal of Higher Education, 73, 94-122

Austin, A. E., \& McDaniels, M. (2006). Preparing the professoriate of the future: Graduate student socialization for faculty roles. In Smart, J. C. (Ed.), Higher education: Handbook of theory and research (Vol. 21 pp. 397-456). Secaucus, NJ: Springer Publishers.

Barnes, B. J., \& Austin, A. E. (2009). The role of doctoral advisors: A look at advising from the advisor's perspective. Innovative Higher Education 33(5), 297-315.

Bollen, K. A., \& Hoyle, R. H. (1990). Perceived cohesion: A conceptual and empirical examination. Social Forces, 69, 479-504

Boud, D., \& Lee, A. (2005). "Peer learning" as pedagogic discourse for research education. Studies in Higher Education, 30(5), 501-516.

Bragg, A. K. (1976). The socialization process in higher education. Washington, DC: ERIC Clearinghouse.

Byars-Winston, A., Estrada, Y., Howard, C., Davis, D., \& Zalapa, J. (2010). Influence of social cognitive and ethnic variables on academic goals of underrepresented students in science and engineering: A multiple-groups analysis. Journal of Counseling Psychology, 57, 205-218.

Byars-Winston, A. M. (2006). Racial ideology in predicting social cognitive career variables for Black undergraduates. Journal of Vocational Behavior, 69, 134-148.

Celeux, G., \& Soromenho, G. (1996). An entropy criterion for assessing the number of clusters in a mixture model. Journal of Classification, 13, 195-212.

Collins, L. M., \& Lanza, S. T. (2010). Latent class and latent transition analysis: With applications in the social, behavioral, and health sciences. Hoboken, NJ: Wiley

Cumming, J. (2009). The doctoral experience in science: Challenging the current orthodoxy. British Educational Research Journal, 35(6), 877-890. 
Curtin, N., Malley, J., \& Stewart, A. J. (2016). Mentoring the next generation of faculty: Supporting academic career aspirations among doctoral students. Research in Higher Education, 57(6), 714-738.

Curtin, N., Stewart, A. J., \& Ostrove, J. M. (2013). Fostering academic self-concept: Advisor support and sense of belonging among international and domestic graduate students. American Educational Research Journal, 50(1), 108-137.

Daniel, C. (2007). Outsiders within: Critical race theory, graduate education and barriers to professionalization. Journal of Sociology and Social Welfare, 34, 25-42

Estrada, M., Woodcock, A., Hernandez, P. R., \& Schultz, P. (2011). Toward a model of social influence that explains minority student integration into the scientific community. Journal of Educational Psychology, 103(1), $206-222$.

Feldon, D. F., Maher, M. A., \& Timmerman, B. E. (2010). Performancebased data in the study of STEM Ph.D. education. Science, 329(5989), 282-283.

Feldon, D. F., Peugh, J., Maher, M. A., Roksa, J., \& Tofel-Grehl, C. (2017a). Time-to-credit gender inequities of first-year PhD students in the biological sciences. CBE-Life Sciences Education, 16, ar4.

Feldon, D. F., Peugh, J., Timmerman, B. E., Maher, M. A., Hurst, M., Strickland, D., ... \& Stiegelmeyer, C. (2011). Graduate students' teaching experiences improve their methodological research skills. Science, 333(6045), 10371039.

Feldon, D. F., Rates, C., \& Sun, C. (2017b). Doctoral conceptual thresholds in cellular and molecular biology. International Journal of Science Education, 39(18), 2574-2593.

Feldon, D. F., Shukla, K. D., \& Maher, M. A. (2016). Faculty-student coauthorship as a means to enhance STEM graduate students' research skills. International Journal for Researcher Development, 7(2), 178-191.

Flores, E. M. (2011). Becoming a researcher: A qualitative study of the apprenticeship model in doctoral education (Unpublished doctoral dissertation). University of Washington, Seattle.

Flores-Scott, E. M., \& Nerad, M. (2012). Peers in doctoral education: Unrecognized learning partners. New Directions for Higher Education, 157 $73-89$.

Gardner, S. K. (2007). "I heard it through the grapevine": Doctoral student socialization in chemistry and history. Higher Education, 54(5), $723-740$.

Gardner, S. K. (2010). Faculty perspectives on doctoral student socialization in five disciplines. International Journal of Doctoral Studies, 5, 39-53.

Gibbs, K. D., \& Griffin, K. A. (2013). What do I want to be with my PhD? The roles of personal values and structural dynamics in shaping the career interests of recent biomedical science PhD graduates. CBE-Life Sciences Education, 12(4), 711-723.

Gibbs, K. D., McGready, J., Bennett, J. C., \& Griffin, K. (2014). Biomedical science Ph.D. career interest patterns by race/ethnicity and gender. PLoS ONE, 9(12), 1-18.

Gildersleeve, R. E., Croom, N. N., \& Vasquez, P. L. (2011). "Am I going crazy?!": A critical race analysis of doctoral education. Equity \& Excellence in Education, 44(1), 93-114.

Golde, C. M. (1998). Beginning graduate school: Explaining first year doctoral attrition. In Anderson, M. (Ed.), The experience of being in graduate school: An exploration (New Directions for Higher Education 101, pp. 55-64). San Francisco: Jossey-Bass.

Golde, C. M. (2000). Should I stay or should I go? Student descriptions of the doctoral attrition process. Review of Higher Education, 23(2), 199-227.

Golde, C. M. (2005). The role of the department and discipline in doctoral student attrition: Lessons from four departments. Journal of Higher Education, 76, 669-700.

Golde, C. M., Bueschell, A. C., Jones, L., \& Walker, G. E. (2009). Advocating apprenticeship and intellectual community: Lessons from the Carnegie Initiative on the Doctorate. In Ehrenberg, R. G., \& Kuh, C. V. (Eds.), Doctoral education and the faculty of the future (pp. 53-64). Ithaca, NY: Cornell University Press.

Griffin, K., Gibbs, K. D., Bennett, J., Staples, C., \& Robinson, T. (2015). "Respect me for my science": A Bordieuian analysis of women scientists' interac- tions with faculty and socialization into science. Journal of Women and Minorities in Science and Engineering, 21, 159-179.

Jaeger, A. J., Haley, K. J., Ampaw, F., \& Levin, J. S. (2013). Understanding the career choice for underrepresented minority doctoral students in science and engineering. Journal of Women and Minorities in Science and Engineering, 19(1), 1-16.

Johnson-Bailey, J., Valentine, T., Cervero, R. M., \& Bowles, T. A. (2009) Rooted in the soil: The social experiences of Black graduate students at a southern research university. Journal of Higher Education, 80(2), 178203

Kardash, C. (2000). Evaluation of undergraduate research experience: Perceptions of undergraduate interns and the faculty mentors. Journal of Educational Psychology, 92, 191-201.

Lanza, S. T., \& Rhoades, B. L. (2013). Latent class analysis: An alternative perspective on subgroup analysis in prevention and treatment. Prevention Science, 14(2), 157-168.

Le, T., \& Gardner, S. K. (2010). Understanding the doctoral experience of Asian international students in the science, technology, engineering, and mathematics (STEM) fields: An exploration of one institutional context. Journal of College Student Development, 51(3), 252-264.

Littlefield, C. M., Taddei, L. M., \& Radosh, M. E. (2015). Organic collaborative teams: The role of collaboration and peer to peer support for part-time doctoral completion. International Journal of Doctoral Studies, 10, 129 142.

Lo, Y., Mendell, N., \& Rubin, D. (2001). Testing the number of components in a normal mixture. Biometrika, 88, 767-778.

Lovitts, B. (2001). Leaving the ivory tower: The causes and consequences of departure from doctoral study. Lanham, MD: Rowman \& Littlefield.

Lunsford, L. (2012). Doctoral advising or mentoring? Effects on student outcomes. Mentoring \& Tutoring: Partnership in Learning, 20(2), 251270.

Magidson, J., \& Vermunt, J. (2002). Latent class models for clustering: A comparison with K-means. Canadian Journal of Marketing Research, 20(1), 36-43.

Maher, M., Wofford, A., Roksa, J., \& Feldon, D. F. (2018). Exploring early exits: Doctoral attrition in the biomedical sciences. Journal of College Student Retention: Research, Theory, \& Practice. https://doi.org/ 10.1177/1521025117736871

Maher, M. A., Gilmore, J. A., Feldon, D. F., \& Davis, T. E. (2013). Cognitive apprenticeship and the supervision of science and engineering research assistants. Journal of Research Practice, 9(2), 1-22

McCoy, D. L., Winkle-Wagner, R., \& Luedke, C. L. (2015). Colorblind mentoring? Exploring white faculty mentoring of students of color. Journal of Diversity in Higher Education, 8(4), 225-242.

Meschitti, V. (2018). Can peer learning support doctoral education? Evidence from an ethnography of a research team. Studies in Higher Education, $43,1-13$.

Millett, C. M., \& Nettles, M. T. (2006). Expanding and cultivating the Hispanic STEM doctoral workforce: Research on doctoral student experiences. Journal of Hispanic Higher Education, 53, 258-287.

Muthén, B., \& Muthén, L. K. (2000). Integrating person-centered and variable-centered analyses: Growth mixture modeling with latent trajectory classes. Alcoholism: Clinical and Experimental Research, 24(6), 882-891.

Muthén, L. K., \& Muthén, B. O. (1998-2017). Mplus user's guide (8th ed.). Los Angeles, CA.

National Science Foundation (NSF). (2015). Science and engineering degrees: 1966-2012. Retrieved August 25, 2019, from www.nsf.gov/ statistics/2015/nsf15326/

NSF. (2017). Survey of graduate students and postdoctorates in science and engineering Fall 2017. Retrieved August 25, 2019, from https:// ncsesdata.nsf.gov/gradpostdoc/2017

Nerad, M., \& Miller, D. S. (1996). Increasing student retention in graduate and professional programs. In Haworth, J. G. (Ed.), Assessing graduate and professional education: Current realities, future prospects (New Directions for Institutional Research 42, pp. 61-76). San Francisco: Jossey-Bass.

Nettles, M. T., \& Millett, C. M. (2006). Three magic letters: Getting to Ph.D. Baltimore, MD: Johns Hopkins University Press. 
Nora, A., \& Cabrera, A. F. (1996). The role of perceptions of prejudice and discrimination on the adjustment of minority students to college. Journal of Higher Education, 67(2), 119-148.

Noy, S., \& Ray, R. (2012). Graduate students' perceptions of their advisors: Is there systematic disadvantage in mentorship? Journal of Higher Education, 83(6), 876-914.

Nylund, K., Asparouhov, T., \& Muthén, B. (2007). Deciding on the number of classes in latent class analysis and growth mixture modeling: A Monte Carlo simulation study. Structural Equation Modeling, 14, 535-569.

Paglis, L. L., Green, S. G., \& Bauer, T. N. (2006). Does adviser mentoring add value? A longitudinal study of mentoring and doctoral student outcomes. Research in Higher Education, 47, 451-476.

Robinson, W. H., McGee, E. O., Bentley, L. C., Houston, S. L., \& Botchway, P. K. (2016). Addressing negative racial and gendered experiences that discourage academic careers in engineering. Computing in Science $\&$ Engineering, 18(2), 29-39.

Roksa, J., Jeong, S., Feldon, D., \& Maher, M. (2018). Socialization experiences and research productivity of Asians and Pacific Islanders: "Model minority" stereotype and domestic vs. international comparison. Research in the Sociology of Education, 20, 155-179.

Rose, G. L. (2005). Group differences in graduate students' concepts of the ideal mentor. Research in Higher Education, 46(1), 53-80.

Ruud, C. M., Saclarides, E. S., George-Jackson, C. E., \& Lubienski, S. T. (2018) Tipping points: Doctoral students and consideration of departure. Journal of College Student Retention: Research, Theory \& Practice, 20(3), 286-307.

Sallee, M. W. (2011). Performing masculinity: Considering gender in doctoral student socialization. Journal of Higher Education, 82(2), 187-216.

Sato, T., \& Hodge, S. R. (2009). Asian international doctoral students' experiences at two American universities: Assimilation, accommodation, and resistance. Journal of Diversity in Higher Education, 2(3), 136-148.

Schroeder, D. S., \& Mynatt, C. R. (1993). Female graduate students' perceptions of their interactions with male and female major professors. Journal of Higher Education, 64, 555-573.

Schroeder, D. S., \& Mynatt, C. R. (1999). Graduate students' relationships with their male and female major professors. Sex Roles, 40(5/6), 393-420.

Schwartz, G. (1978). Estimating the dimension of a model. Annals of Statistics, 6, 461-464.
Seagram, B. C., Gould, J., \& Pyke, S. W. (1998). An investigation of gender and other variables on time to completion of doctoral degrees. Research in Higher Education, 39(3), 319-335.

Stephan, P. (2012). How economics shapes science. Cambridge, MA: Harvard University Press.

Takashiro, N. (2017). Asian international graduate students' extrinsic motivation to pursue degrees. Psychological Thought, 10(1), 178-189.

Taylor, E., \& Antony, J. S. (2000). Stereotype threat reduction and wise schooling: Towards the successful socialization of African American doctoral students in education. Journal of Negro Education, 69(3), 184-198.

Tenenbaum, H. R., Crosby, F. J., \& Gliner, M. D. (2001). Mentoring relationships in graduate school. Journal of Vocational Behavior, 59(3), 326-341.

Tinto, V. (1993). Leaving college: Rethinking the causes and cures of student attrition (2nd ed.). Chicago, IL: University of Chicago Press.

Turner, J. L., Miller, M., \& Mitchell-Kernan, C. (2002). Disciplinary cultures and graduate education. Emergences, 12(1), 47-70.

Twale, D. J., Weidman, J. C., \& Bethea, K. (2016). Conceptualizing socialization of graduate students of color: Revisiting the Weidman-Twale-Stein framework. Western Journal of Black Studies, 40(2), 80-94.

Vuong, Q. (1989). Likelihood ratio tests for model selection and non-nested hypotheses. Econometrica, 57, 307-333.

Weidman, J. C. (2010). Doctoral student socialization for research. In Gardner, S. K., \& Mendoza, P. (Eds.), On becoming a scholar: Socialization and development in doctoral education (pp. 45-55). Sterling, VA: Stylus.

Weidman, J. C., \& Stein, E. L. (2003). Socialization of doctoral students to academic norms. Research in Higher Education, 44(6), 641-656.

Weidman, J. C., Twale, D. J., \& Stein, E. L. (2001). Socialization of graduate and professional students in higher education-A perilous passage? (ASHEERIC Higher Education Report 28). San Francisco, CA: Jossey-Bass.

Williams, S. N., Thakore, B. K., \& McGee, R. (2016). Career coaches as a source of vicarious learning for racial and ethnic minority $\mathrm{PhD}$ students in the biomedical sciences: A qualitative study. PLOS ONE, 11(7), e0160038.

Zhang, Y. (2016). International students in transition: Voices of Chinese doctoral students in a US research university. Journal of International Students, 6(1), 175-194.

Zhao, C. M., Golde, C. M., \& McCormick, A. C. (2007). More than a signature: How advisor choice and advisor behaviour affect doctoral student satisfaction. Journal of Further and Higher Education, 31(3), 263-281. 